\title{
Improving the use of unbound granular materials in railway sub-ballast layer
}

\author{
E. Fortunato, A. Paixão \& S. Fontul \\ Laboratório Nacional de Engenharia Civil, Lisbon, Portugal
}

\begin{abstract}
The rational use of materials to be applied in the supporting layers of railway tracks is an important aspect that can contribute to reduce the life cycle cost of such infrastructure. In recent construction and renewal rail track projects carried out in Portugal, the sub-ballast layer has been typically implemented in the track structure, using Unbound Granular Materials (UGM). This layer and the characteristics of the materials play a fundamental role in the track behaviour. Nevertheless, there is a lack of consensus worldwide on the requirements established for such materials. In Portugal and in other European countries, very stringent requirements based on empirical tests have been adopted, making it difficult to find materials that fulfil such requirements. There is also evidence that some of these materials, which do not comply with all the requirements, can still be considered as appropriate for sub-ballast. Within the scope of this study, the construction of a new railway section was supervised. During construction, it was difficult to obtain the desired quantity of granite material for the $30 \mathrm{~cm}$ thick sub-ballast layer that would fulfil the requirements and still comply with the contract deadline. As an alternative, another structural solution was used that considered the replacement of the bottom $15 \mathrm{~cm}$ of granite material subballast layer by limestone material which did not comply with some requirements. In order to study the feasibility of this change, to evaluate its consequences and establish new quality assurance indicators to be adopted afterwards, several studies were developed, such as in situ characterization and cyclic triaxial load tests on different UGM. The studies performed and the results presented in this paper show that, taking into account a mechanistic approach, some materials that do not comply with all requirements based on empirical tests might present adequate performance to be applied in the sub-ballast.
\end{abstract}

